\title{
Conhecimentos sobre boas práticas em cozinhas domiciliares através de um questionário on- line
}

\section{Knowledge about good practices in home kitchens through an online questionnaire}

\author{
Felipe da Costa Rolim ${ }^{1}$, Vivian Antunes Beneri ${ }^{2}$, Cleber Bastos Rocha ${ }^{3}$, Antônio César \\ Corrêa $^{4}$ \\ 1. Universidade Federal do Rio Grande, e-mail: feliperolim@live.com; ${ }^{2}$ Universidade Federal do \\ Rio Grande, e-mail: vivian.beneri.84@gmail.com; ${ }^{3 \cdot}$ Universidade Federal de Pelotas, e-mail: \\ cbr.vet@gmail.com; ${ }^{4}$. Universidade Norte do Paraná, e-mail: antonio.correa@ \\ E-mail do autor correspondente: feliperolim@live.com
}

Resumo - As Doenças Transmitidas por Alimentos (DTA) são aquelas causadas pela ingestão de alimentos e/ou água contaminados. A ocorrência de DTA está relacionada com diversos fatores, como: aquisição de alimentos adequados para o consumo, condições de saneamento e qualidade da água, boas práticas de manipulação de alimentos, dentre outros. A maioria dos surtos alimentares no Brasil ocorre com o consumo de alimentos produzidos nas residências. $\mathrm{O}$ objetivo do presente estudo foi avaliar o conhecimento sobre boas práticas de manipulação de alimentos em cozinhas domiciliares. Foram elaboradas 11 questões e disponibilizadas nas redes sociais por 30 dias através do método Snow ball Sampling. Entre os itens do questionário estavam as boas práticas na manipulação da carne de frango, higienização das mãos, descongelamento de alimentos, higienização e contaminação de utensílios como esponja de lavar louças e tábua para corte de alimentos, cuidados no armazenamento de alimentos, preocupação quanto aos riscos de DTAs. Foram contabilizadas 100 respostas ao questionário. Os participantes demonstraram ter um mínimo de conhecimento sobre boas práticas na manipulação dos alimentos. Entretanto, falham no que tange a higienização da esponja de lavar louças, manipulação da carne de frango, descongelamento de alimentos e possuir apenas uma tábua de corte para diferentes tipos de alimentos. A adoção de medidas simples de higiene pode prevenir a ocorrência das DTAs nas residências. Desta forma, se faz necessário a atuação em educação sanitária para manipuladores de alimentos em cozinhas domiciliares.

Palavras-chave: Surtos; doenças; manipulação. 


\begin{abstract}
Foodborne Diseases are those caused by ingestion of contaminated food and /or water. The occurrence of foodborne diseases is related to several factors, such as: acquisition of food suitable for consumption, sanitation conditions and water quality, good food handling practices, among others. Most food outbreaks in Brazil occur with the consumption of food produced in households. The aim of the present study was to evaluate the knowledge on good food handling practices in home kitchens. 11 questions were elaborated and made available on social networks for 30 days through the Snow ball Sampling method. Among the items of the questionnaire were good practices in handling chicken meat, hand hygiene, food defrosting, hygiene and contamination of utensils such as dishwashing sponge and cutting board, food storage care, concern about foodborne diseases risks. There were 100 answers to the questionnaire. Participants demonstrated a minimum of knowledge of good food handling practices. However, they fail to clean the dishwasher sponge, handle chicken meat, defrost food and have only one cutting board for different types of food. Thereby, simple measures hygiene can prevent the occurrence of foodborne diseases in households. Thus, it is necessary to perform health education for food handlers in home kitchens.
\end{abstract}

Keywords: Outbreaks; diseases; manipulation

\title{
Introdução
}

A prevenção das doenças transmitidas por alimentos (DTAs) é uma preocupação constante nos órgãos de vigilância sanitária. De acordo com o Ministério da Saúde (2010) a ocorrência de DTAs vem aumentando de modo significativo em nível mundial. Vários são os fatores que contribuem para a emergência dessas doenças, entre os quais destacam-se: o crescente aumento das populações; a existência de grupos populacionais vulneráveis ou mais expostos; o processo de urbanização desordenado e a necessidade de produção de alimentos em grande escala.

Os alimentos possuem um papel fundamental na economia de qualquer país e o investimento em políticas públicas voltadas à educação sanitária, produção de alimentos seguros e efetiva atuação dos sistemas de vigilância são alternativas úteis na divulgação, conscientização, prevenção e controle deste tipo de enfermidade (Melo et al. 2018). 
A distribuição dos surtos de DTAs no Brasil entre os anos 2009 e 2018 por local de ocorrência foi de 36,9\% nas residências, seguido por restaurantes/padarias e similares com 15,8\% (Ministério da Saúde, 2010). Em um estudo realizado por Welker et al (2010) sobre surtos alimentares ocorridos no estado do Rio Grande do Sul as residências foram o principal local de ocorrência dos surtos (43\%), seguidas de estabelecimentos comerciais (18\%) e refeitórios de empresas (14\%).

Estudos nacionais e internacionais relatam que a maioria dos casos de DTAs não são notificados às autoridades sanitárias, devido ao fato de que muitos dos patógenos presentes nos alimentos causam sintomas brandos, levando a vítima a não buscar ajuda médica (Sirtoli \& Comarella, 2018). Desta forma, evidencia-se a necessidade de estudos sobre boas práticas de manipulação em cozinhas domiciliares e medidas educativas para reduzir os riscos associados a alimentos contaminados.

O objetivo deste trabalho foi verificar o conhecimento da população sobre alguns pontos de risco na cozinha associados a ocorrência de doenças transmitidas por alimentos (DTAs) e adoção de boas práticas na manipulação em cozinhas domiciliares através de um questionário on-line.

\section{Material e Métodos}

Foi realizado um levantamento quali-quantitativo, através da metodologia Snowball Sampling ou bola de neve, onde os participantes da pesquisa recrutam outros participantes para um teste. Para a pesquisa utilizou-se um questionário on-line (Google formulários) divulgado por redes sociais para a população em geral. Os participantes não foram identificados, tratandose de uma pesquisa de opinião.

O questionário foi composto por 11 perguntas de múltipla escolha com o tema relacionado a boas práticas de manipulação em uma cozinha domiciliar e ficou disponível para participação durante um período de 30 dias. Entre os itens do questionário estavam as boas práticas na manipulação da carne de frango, higienização das mãos, método de higienização de vegetais, descongelamento de alimentos, higienização e contaminação de utensílios como esponja de lavar louças, tábua para corte de alimentos, cuidados no preparo de alimentos, 
conhecimento sobre doenças de transmissão alimentar e sua preocupação quanto aos riscos destas doenças.

A tabulação dos dados foi realizada no programa Excel e analisados através de porcentagem com geração de tabelas e gráficos.

O projeto foi aprovado pelo colegiado do Núcleo Municipal da Educação em Saúde Coletiva (NUMESC) deferido de acordo com o parecer 022/2019.

\section{Resultados e Discussão}

Após 30 dias da disponibilização dos participantes na pesquisa esta foi encerrada e contabilizada a participação de 100 respostas. Quanto ao procedimento de higienização da esponja de lavar louça, 60\% dos pesquisados não acha importante, conforme Figura 1.

Figura 1. Procedimento de higienização da esponja de lavar louça na residência dos participantes (\%).

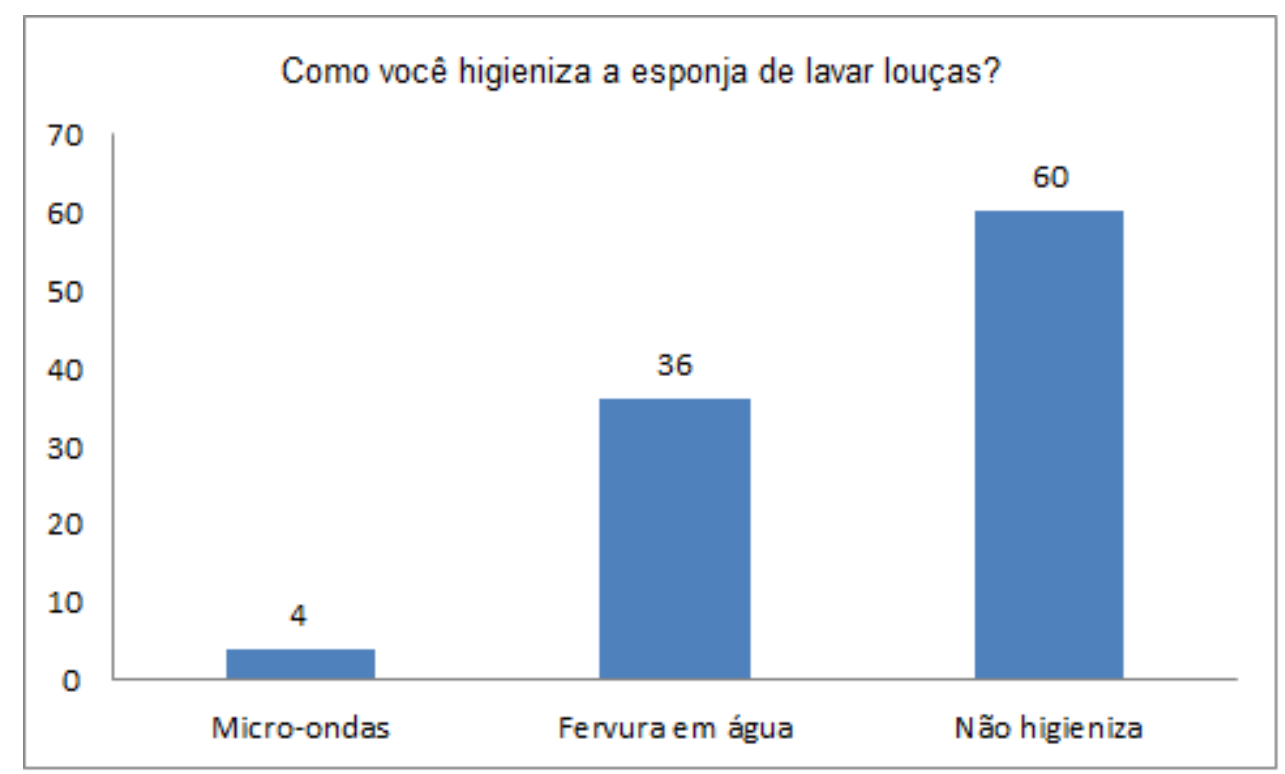

Resultados semelhantes foram observados por Moura et al. (2017), onde 87,5\% da população de Teresina-PI não adotava práticas de desinfecção das esponjas utilizadas em cozinhas domésticas. 
Simon \& Benedetti (2016) avaliaram nove amostras de esponjas utilizadas em restaurantes, observando que $77,77 \%$ estavam contaminadas por coliformes totais e $44,44 \%$ por coliformes termotolerantes, além disso o método de fervura eliminou $100 \%$ da carga microbiológica das amostras. Rocha \& Moreira (2016), observaram que entre 10 esponjas avaliadas $60 \%$ estavam contaminadas com coliformes fecais e todas as esponjas que apresentaram contaminação tinham entre quatro e seis dias de uso. Nesso \& Lembo (2012) relatam que a utilização de esterilizador próprio para micro-ondas por oito minutos foi suficiente para eliminar a contaminação inicial das esponjas.

Desta forma, evidencia-se o desconhecimento da população sobre boas prática em cozinha domiciliares, visto que uma medida simples, como fervura em água por cinco minutos pode evitar a contaminação cruzada da esponja com os alimentos.

Outro utensílio bastante utilizado na cozinha doméstica com risco de contaminação cruzada é a tábua de corte de alimentos. De acordo com o Figura 2 a maioria dos participantes da pesquisa utilizam tábua de vidro (38\%) seguidas pela madeira (33\%) e plástico (29\%). Este resultado demonstra que a maioria dos participantes possui tábuas de corte de material de fácil higienização (vidro e plástico).

Figura 2. Tipo de tábua de corte utilizada nas residências dos participantes (\%).

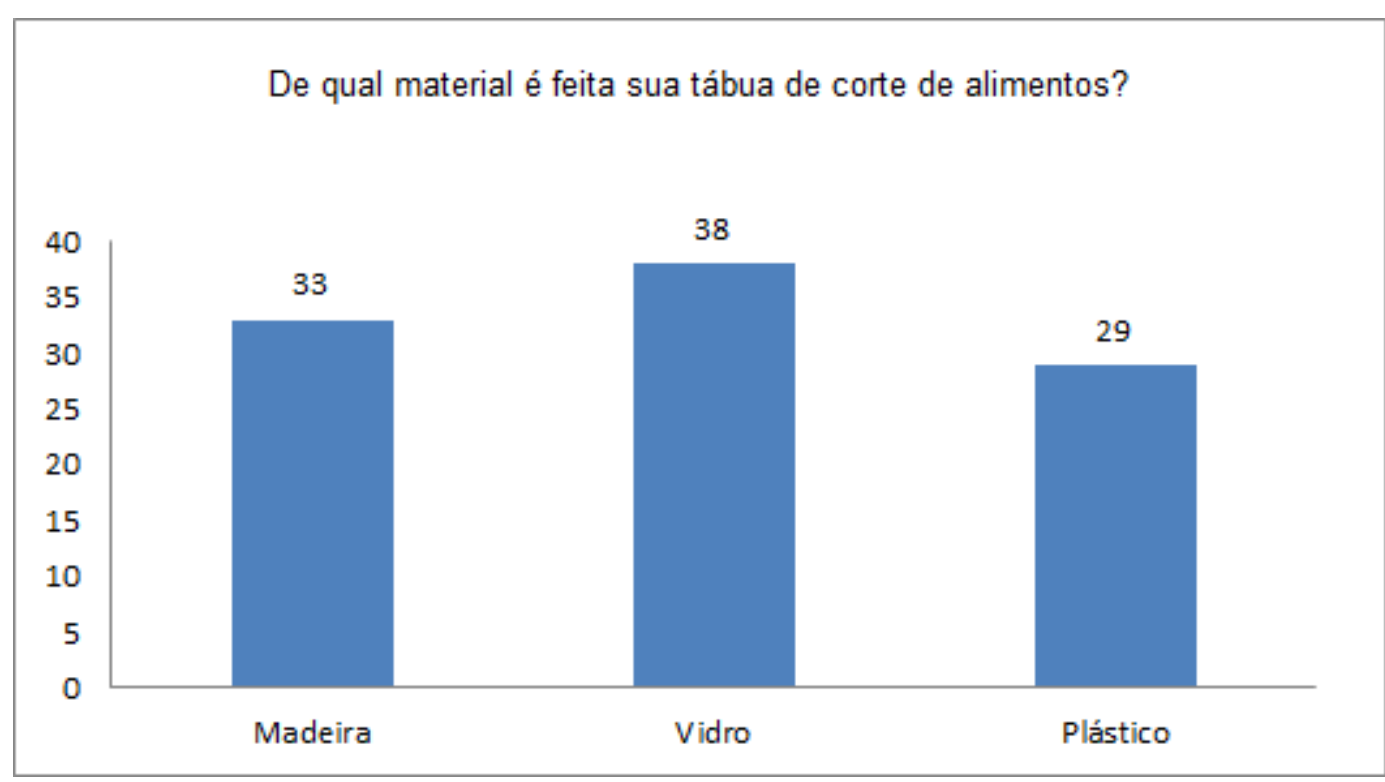


A RDC 216 (Anvisa, 2004) que regulariza as boas práticas para serviços de alimentação preconiza que utensílios utilizados para alimentos devem ser de material liso, impermeável, lavável e estar isentos de rugosidades, frestas e outras imperfeições que possam comprometer a higienização dos mesmos. Desta forma, excluindo utensílios de madeira, bambu ou material semelhante. Souza et al. (2017) observaram que somente adotando práticas adequadas de higienização das superfícies de corte podem reduzir a contaminação microbiológica.

Observa-se na Tabela 1 que $89 \%$ dos participantes utilizam a mesma tábua de corte para alimentos crus e prontos para consumo. Resultados semelhantes foram observados por Leite et al. (2009) onde 73\% das residências pesquisadas utilizavam a mesma tábua de corte para diferentes alimentos. Desta forma a higiene correta deste utensílio torna-se essencial para redução da contaminação cruzada.

De acordo com Medeiros et al. 2015, Campylobacter jejuni e Campylobacter coli constituem as espécies termofílicas mais frequentemente isoladas em casos de enterites humanas, devido à ingestão de alimentos à base de frango mal cozido ou através da contaminação cruzada durante a manipulação de alimentos crus.

Quanto a utilização de ovos crus, 68\% dos participantes responderam não utilizar na produção de maioneses caseiras (Tabela 1). Marchi et al. (2011) avaliando a ocorrência de surtos em Santa Catarina entre os anos de 1995 e 2007 observaram que a bactéria Salmonella $s p$. foi o agente etiológico mais frequente (54\%) e a maionese o alimento mais implicado nos surtos $(32,7 \%)$.

Quando questionados sobre o consumo de alimentos coloniais sem inspeção a maioria dos participantes (61\%) também demonstrou bons hábitos de saúde, não consumindo tais produtos. Ao analisar o local de produção dos alimentos, Klein et al. (2017) verificaram que os surtos se desencadeiam em sua maioria nas residências ou estabelecimentos comerciais, principalmente por matéria-prima sem inspeção, seguido de manutenção inadequada dos alimentos por longos períodos em temperatura ambiente.

Nos questionamentos referentes à lavagem de mãos durante a manipulação (Tabela 1) verificou-se que $81 \%$ dos pesquisados lavam as mãos entre um alimento e outro, entretanto $54 \%$ lavam a carne de frango antes de cozinhá-la, mostrando desconhecimento quanto aos riscos de contaminação cruzada por diversos tipo de bactérias, incluindo a salmonella e a Campylobacter. 
Tabela 1. Questionário e resposta da população sobre conhecimento e boas práticas em cozinhas domésticas $(\%)$

\begin{tabular}{|l|c|c|}
\hline Questionamentos & $\begin{array}{c}\text { Sim } \\
(\%)\end{array}$ & $\begin{array}{c}\text { Não } \\
(\%)\end{array}$ \\
\hline Você costuma fazer maionese caseira com ovos crus? & 32 & 68 \\
\hline $\begin{array}{l}\text { Você possui uma tábua de corte para alimentos crus e outra para } \\
\text { alimentos prontos? }\end{array}$ & 11 & 89 \\
\hline $\begin{array}{l}\text { Você tem o hábito de comprar alimentos coloniais sem inspeção? } \\
\text { Você lava a carne de frango antes de cozinhar? }\end{array}$ & 39 & 61 \\
\hline $\begin{array}{l}\text { Você já teve sintomas como diarréia ou vômito causado pelo consumo de } \\
\text { alimentos mal manipulados? }\end{array}$ & 56 & 44 \\
\hline Você lava as mãos entre a manipulação de um alimento e outro? & 81 & 19 \\
\hline
\end{tabular}

$\mathrm{n}=100$ participantes

Uma das recomendações mais importantes para os consumidores é a de não lavar a carne das aves antes de a cozinhar, uma vez que ao procedermos à sua lavagem, pode-se disseminar bactérias por diversos equipamentos e utensílios da cozinha (Padilha, 2015). Nunes et al. (2017) relatam que durante a investigação de um surto alimentar no estado de São Paulo, a suspeita de contaminação cruzada ocorreu devido a má manipulação de aves da ceia natalina, utensílios, pia e bancadas onde também foi produzido um bolo.

A RDC N ${ }^{\circ} 13$, de 02 de janeiro de 2001, regulamenta sobre a obrigatoriedade para os produtores de carne de aves e seus miúdos crus, resfriados ou congelados de incluir na rotulagem destes produtos as instruções de uso, preparo e conservação, como recomendações, que auxiliem o consumidor no controle do risco associado ao consumo de alimentos nos quais o microrganismo Salmonella sp. possa estar presente.

Dentre os surtos de salmonelose humana, o ovo pode destacar-se como um dos principais alimentos veiculadores. O fato de que ovos crus são utilizados, entre outros, para produção de maionese caseira, por exemplo, deve ser considerado (Amson, 2006). 
A maioria dos participantes descongela os alimentos em temperatura ambiente (50\%), seguido por micro-ondas (36\%) e geladeira (14\%), demonstrando desconhecimento quanto aos riscos da multiplicação bacteriana quando expostos a longos períodos em temperatura inadequada (Figura 3). Este resultado difere dos observados por Fortunato e Vicenzi (2014) onde $52,5 \%$ dos entrevistados descongela os alimentos de forma adequada (geladeira e microondas).

Figura 3. Método de descongelamento de alimentos (\%).

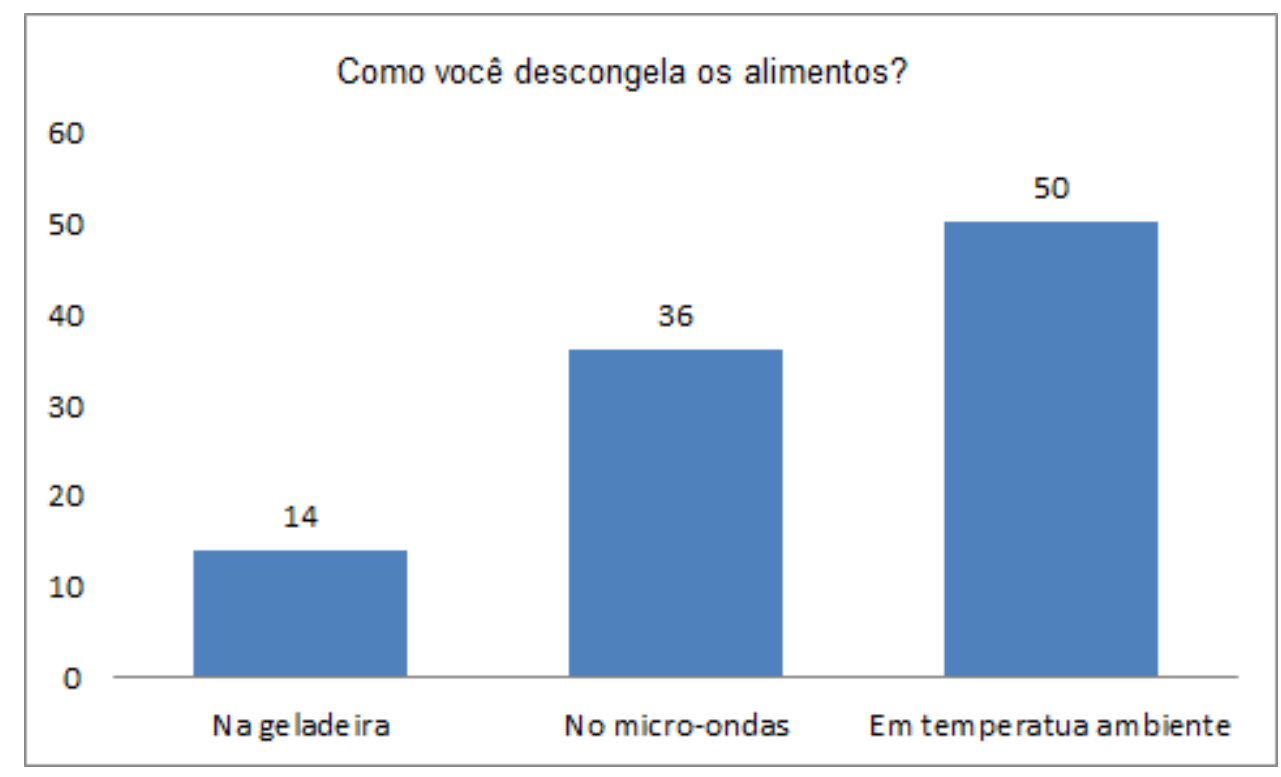

A maioria dos participantes realiza de forma correta a organização dos alimentos na geladeira (Figura 4), ou seja, colocando os alimentos que exigem menor temperatura e que não sofrerão aquecimento na prateleira superior $(61 \%)$, contra $37 \%$ e $2 \%$ que indicaram outros produtos. 
Figura 4. Forma de organização dos alimentos no refrigerador (\%).

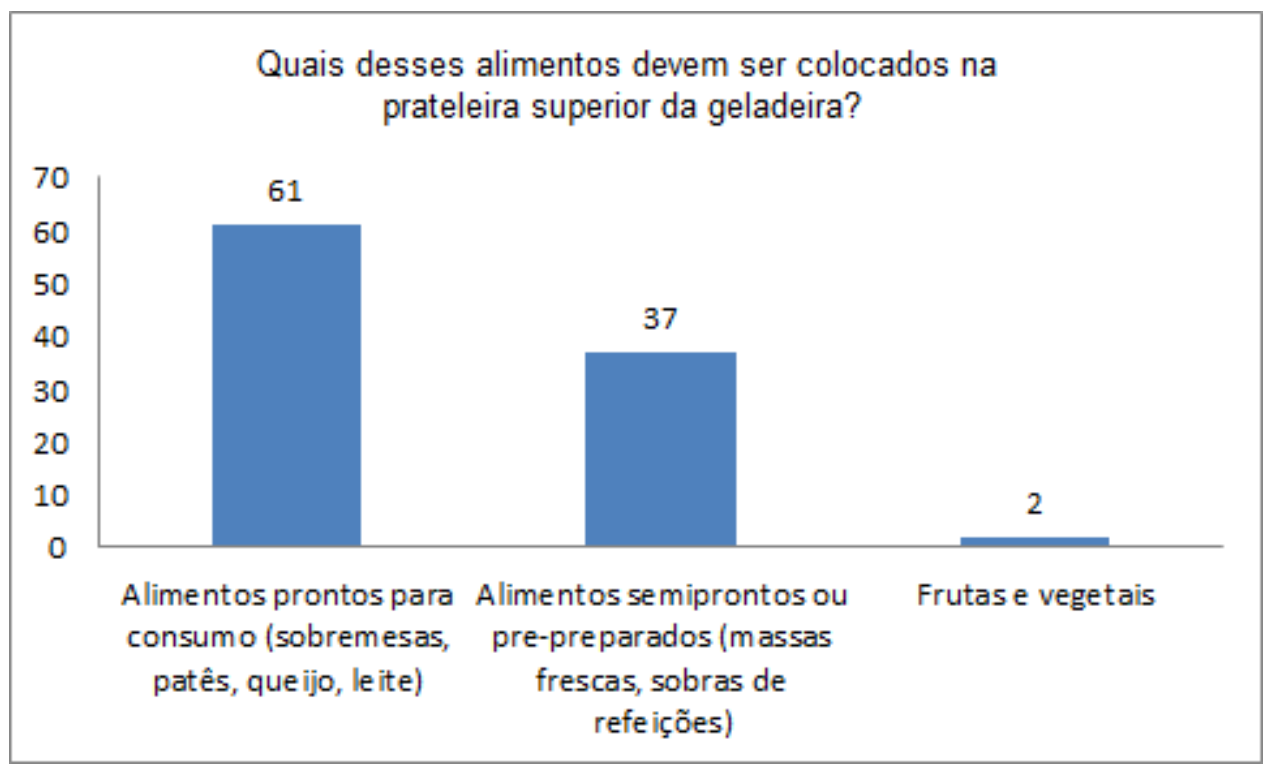

Entre os participantes da pesquisa, 39\% demonstraram grande preocupação com as doenças transmitidas por alimentos (Figura 5).

Figura 5. Perfil de preocupação dos participantes quanto a doenças transmitidas por alimentos $(\%)$.

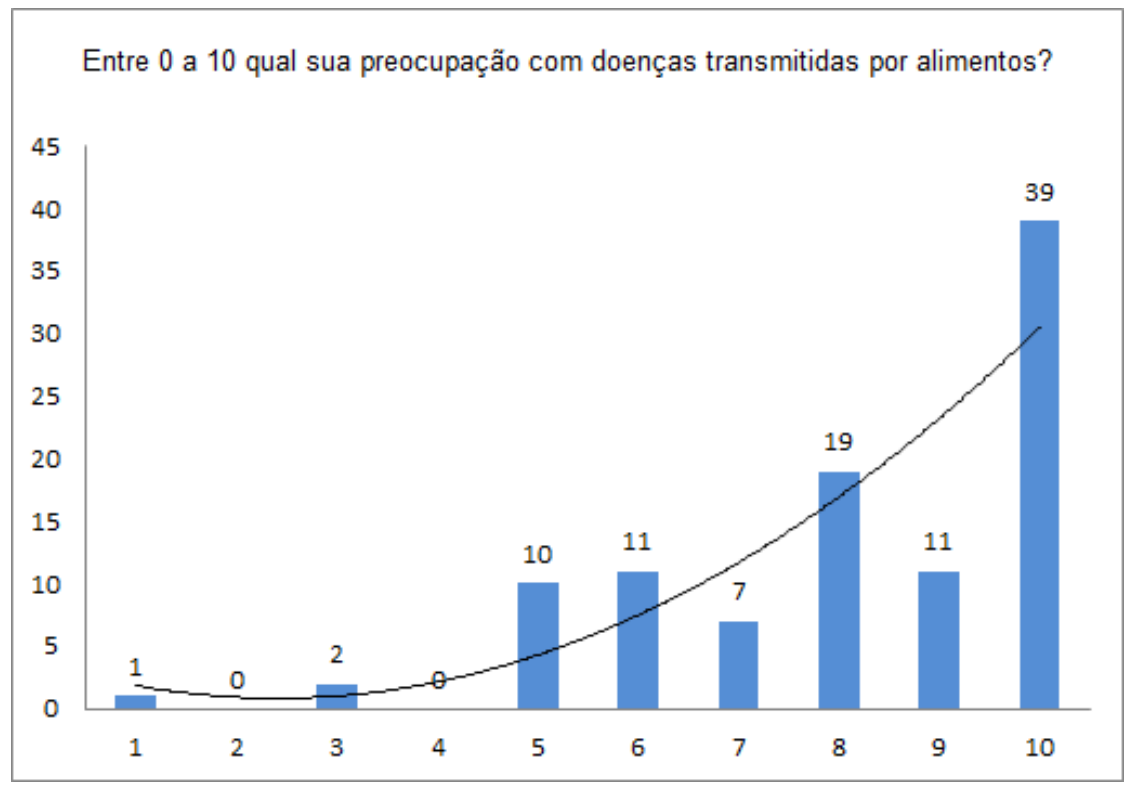


Resultados semelhantes foram observados por Andrade et al. (2013) onde os consumidores demonstram grande preocupação com os riscos associados à contaminação, sejam estes químicos ou microbiológicos, com tendência para maior preocupação associada aos riscos químicos.

\section{Conclusão}

De forma geral os participantes demonstraram adotar boas práticas na manipulação dos alimentos, exceto quanto a higienização da esponja de lavar louças, manipulação da carne de frango, descongelamento de alimentos e possuir apenas uma tábua de corte para diferentes tipos de alimentos.

A adoção de medidas simples de higiene pode prevenir a ocorrência das DTAs nas residências. Desta forma, se faz necessário a atuação em educação sanitária para manipuladores de alimentos em cozinhas domiciliares.

\section{Conflito de interesses}

Os autores deste manuscrito não declararam conflitos de interesse. 


\section{Referencias}

Agência Nacional de Vigilância Sanitária - Anvisa. Resolução RDC No 13, de 2 de janeiro de 2001. Aprova o Regulamento Técnico para Instruções de Uso, Preparo e Conservação na Rotulagem de Carne de Aves e Seus Miúdos Crus, Resfriados ou Congelados, em Anexo. Diário Oficial União.2 jan 2001.

AMSON, G.V., HARACEMIV, S.M.C., MASSON \& M.L. Levantamento de dados epidemiológicos relativos à ocorrências/surtos de doenças transmitidas por alimentos (DTAs) no estado do Paraná - Brasil, no período de 1978 a 2000. Ciência e Agrotecnologia, v.30, n.6, (2006). p. 1139-1145.

ANDRADE, J.C., DELIZA, R., YAMADA, E.A., GALVÃO, M.T.E.L., FREWER, L.J., \& BERAQUET, N.J. Percepção do consumidor frente aos riscos associados aos alimentos, sua segurança e rastreabilidade. Brazilian Journal Of Food Technology, [S.L.], v. 16, n. 3, (2013) p. 184-191.

BRASIL. Ministério da Saúde. Secretaria de Vigilância em Saúde. Departamento de Vigilância Epidemiológica.Manual integrado de vigilância, prevenção e controle de doenças transmitidas por alimentos / Ministério da Saúde, Secretaria de Vigilância em Saúde, Departamento de Vigilância Epidemiológica. - Brasília: Editora do Ministério da Saúde, 2010. 158 p. : il. - (Série A. Normas e Manuais Técnicos).

FORTUNATO, L.H. \& VICENZI, K. Conhecimento sobre práticas de higiene na manipulação de alimentos em residências de caxias do sul - RS. Revista Uningá Review, v.17,n.1, (2014). p.42-47.

KLEIN, L.R., BISOGNIN, R.P. \& FIGUEIREDO, D.M.S. Estudo do perfil epidemiológico dos surtos de doenças de transmissão hídrica e alimentar no Rio Grande do Sul: uma revisão dos registros no Estado. Hygeia - Revista Brasileira de Geografia Médica e da Saúde, v.13, n. $25,(2017) \cdot$ p.48 - 64.

LEITE, L.H.M., MACHADO, P.A.N., VASCONCELLOS, A.L.R. \& CARVALHO, I.M. Boas práticas de higiene e conservação de alimentos em cozinhas residenciais de usuários do programa saúde da família-Lapa. Revista de Ciências Médicas, v. 18, n.2, (2009). p.81-88, 
MARCHI, D.M., BAGGIO, N., TEO, C.R.P.A. \& BUSATO, M.A. Ocorrência de surtos de doenças transmitidas por alimentos no Município de Chapecó, Estado de Santa Catarina, Brasil, no período de 1995 a 2007. Epidemiologia e Serviços de Saúde, v. 20, n.3, (2011). p.401407.

MEDEIROS, V.M., BRICIO, S.M.L., CLEMENTINO \& M.M. Identificação de Campylobacter jejuni e Campylobacter coli isoladas de carcaças resfriadas de Frango pela Multiplex PCR. Vigilância Sanitária em Debate: Sociedade, Ciência \& Tecnologia, V.3, n.3. (2015). doi.org/10.3395/2317-269x.00363

MELO, E.S., AMORIM, W.R., PINHEIRO, R. E. E., CORRÊA, P.G.N., CARVALHO, S.M.R., SANTOS, A.R.S.S., BARROS, D.S., OLIVEIRA, E.T.A.C., MENDES, C.A. \& SOUZA, F.V. Doenças transmitidas por alimentos e principais agentes bacterianos envolvidos em surtos no Brasil: revisão. Pubvet, v.12, n.10, (2018). a191, p.1-9.

MOURA, D.M.B, SOARES, V.H.C.O, BESERRA \& M.L.S. Análise microbiológica, formas de uso e desinfecção de esponjas de uso doméstico na cidade de Teresina, PI. Higiene Alimentar, v. 31, n. 272/273, (2017). p.272-273.

NESSO, N. \& LEMBO, T. O uso do forno de micro-ondas como agente antimicrobiano de alguns utensílios domésticos. Journal of the Health Sciences Institute, v. 30(4), (2012). p.315-7.

NUNES, S.M., CERGOLE-NOVELlA, M.C., TIBA, M.R., ZANON, C.A., BENTO, I.S.S., PASCHUALINOTO, A.L., THOMAS, I., SILVA, A.A. \& WALENDY, C.H. Surto de doença transmitida por alimentos nos municípios de Mauá e Ribeirão Pires - SP. Higiene Alimentar, v.31, (2017). n.264/265.

PADILHA, P.M.O. Campylobacter na produção de carne de frango e saúde pública: revisão bibliográfica [Dissertação]. Coimbra: Escola Universitária Vasco da Gama. (2015).

ROCHA, M. \& MOREIRA, M.R. Qualidade higiênico-sanitária de esponjas utilizadas em unidades de alimentação e nutrição em Fortaleza, Ceará. Revista de Nutrição e Vigilância em Saúde, (2016). v.3(2).

SIMON, D. \& BENEDETTI, V.P. Avaliação da contaminação microbiológica de esponjas utilizadas em serviços de alimentação da cidade de Marmeleiro- PR. Higiene Alimentar, v. 30 , n. 258/259, (2016). p.272-273 
SIRTOLI, B.D. \& COMARELLA, L. O papel da vigilância sanitária na prevenção das doenças transmitidas por alimentos (DTA). Revista Saúde e Desenvolvimento, (2018). v.12, n.10.

SOUZA, V.R., PRIETO, A.H., SANTOS, D.M., ABRAHÃO, W.M., BORGES, E.M.J. \& LOPES, M.O. Avaliação das condições higiênicas de superfícies de corte de carnes em supermercados de um município da região metropolitana de Curitiba-PR. Archives of Veterinary Science, v.22, n.1, (2017). p.01-09.

WELKER, C.A.D., BOTH, J.M.C., LONGARAY, S.M., HAAS, S., SOEIRO, M.L.T. \& RAMOS, R.C. Análise microbiológica dos alimentos envolvidos em surtos de doenças transmitidas por alimentos (DTA) ocorridos no estado do Rio Grande do Sul, Brasil. Revista Brasileira de Biociência, v. 8, n. 1, . (2010). p. 44-48. 